\title{
Design of pitch angle controller for wind turbine based on pi neurofuzzy model
}

\author{
Ammar A. Aldair ${ }^{1}$, Mofeed T. Rashid ${ }^{2}$, Ali F. Halihal ${ }^{3}$, Mastaneh Mokayef ${ }^{4}$ \\ ${ }^{1,2}$ Department of Electrical Engineering, Faculty of Engineering, Basrah University, Iraq \\ ${ }^{3}$ Nassiriyah Thermal Power Plant, Iraq \\ ${ }^{4}$ Department of Electrical Engineering, Faculty of Engineering and Built Environment (FETBE), \\ UCSI University, Malaysia
}

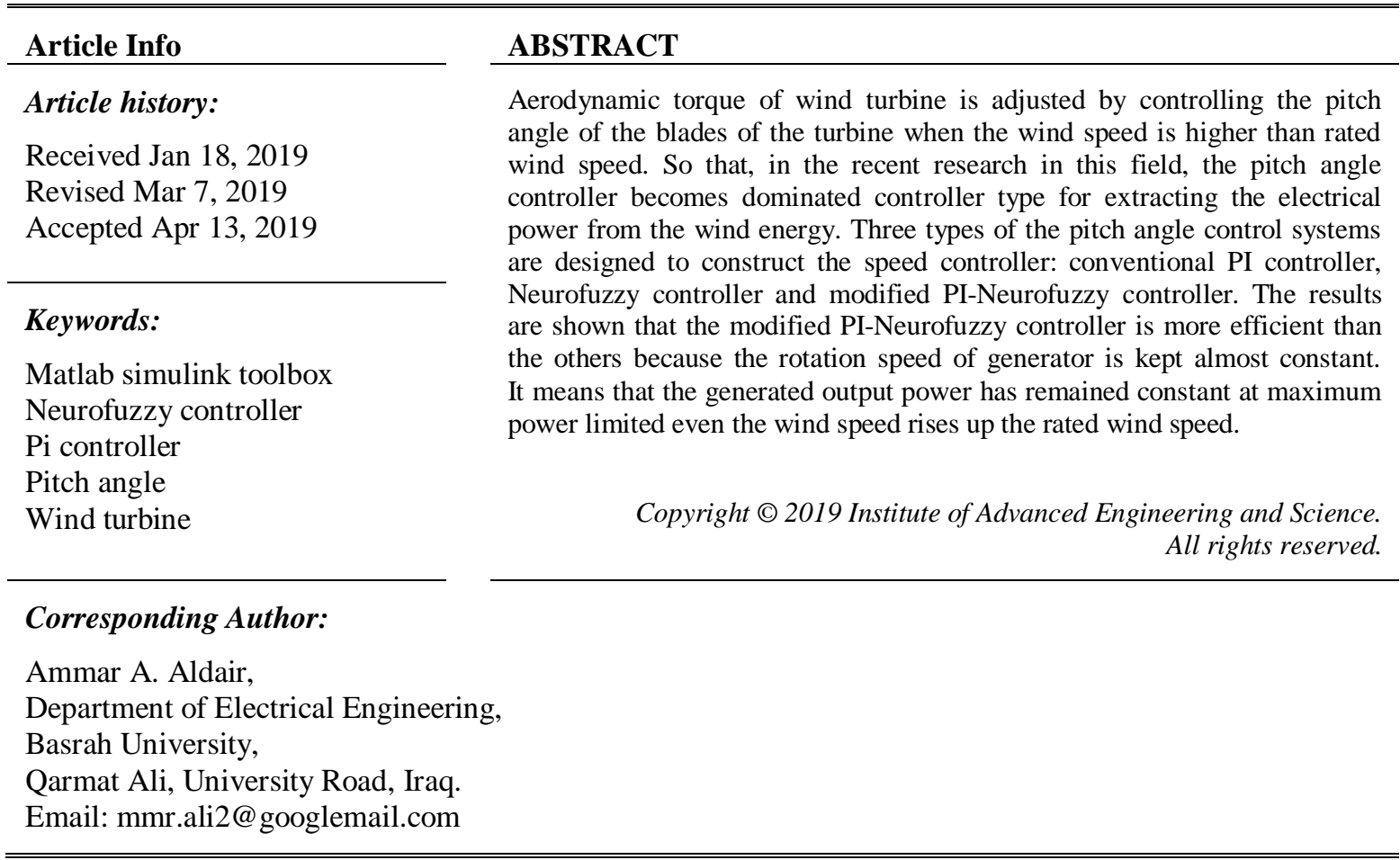

\section{INTRODUCTION}

In the recent year, decreasing the fossil fuel consumption and detraction harmful emission become the important topics for many researchers to reduce the effects of climate change [1]. To achieve this task, most of the researchers in this field trend using the renewable energy such as: wind energy [2-4], solar energy [5-8], wave energy [9-10] etc. instead of the fossil fuels to protect the environment. The wind energy is one type of renewable energy that is available in most of countries around the world. Therefore, many researches are achieved to extract the electrical power from the wind energy. Because of the wind speed is a variable amount during the day; the pitch variable-speed control wind turbines strategy is studied. This control strategy has typically two types. If wind speed is less than the rated wind speed of the turbine, the designed pitch control system adjusts the pitch angle of the blades to keep the rotation speed of the generator at a constant level to extract maximum electrical power from the wind energy for improving the efficiency of wind turbine. While, when the wind speed is higher than the rated wind speed of the turbine, the pitch angle control system is required to maintain the rotation speed of the generator almost constant. Due to the generated power from the wind turbine is very sensitive against changing the pitch angle of the blade, a robust controller pitch angle should be designed. It is clear that the wind speed fluctuates during the day, so that if the wind turbine has no pitch angle control system, the generated electrical power will fluctuate as well. Therefore, when speed of the wind is higher than the rated speed of the turbine, the generated electrical power will be very high that may cause the crashing of the wind turbine system. For that reason the intelligent pitch angle controller should be designed carefully. 
The purpose of designing a speed pitch angle control system may be listed in following main points: a) Extracting the maximum electrical energy when the wind speed is below the rated.

b) Remaining the rotational of the generator at the designed level when the wind speed is higher than the rated.

Many researches are achieved to improve the designing of the pitch angle control system. The National Renewable Energy Laboratory wind turbine simulator is utilized to design a dynamic chattering torque control and a proportional integral (PI) pitch control system [11]. The root locus method is used to design a PID pitch angle controller for a fixed speed active-stall wind turbine [12]. The back propagation learning algorithm is used for learning and training the parameters of the adaptive neurofuzzy inference system to design and estimate the optimal power coefficient value of wind turbines [13]. In reference [14], the authors present adaptive neurofuzzy inference system controlled doubly fed induction generator based wind energy conversion system integration with the grid for enhancement of wind turbine performance. Fuzzy logic pitch angle controller is designed for variable speed wind turbine [15-18]. In reference [19], a new scheme is developed from the wind turbine's MPPT-curve to extract maximum power from the wind turbine system. A constant power control system is proposed for a wind turbine to provide constant power output and compensate the deviations between the desired active power output and the available wind energy input [20]. Two controllers (PI Controller and LQR Controllers) are proposed for secondary regulation of Load Frequency Control with the participation of variable-speed wind turbines to maximize the generated power from the wind turbine [21]. Nonlinear sliding mode control with exponential reaching law control is used to improve the performance of wind turbines by producing electrical energy from wind energy [22]. Backstopping and Sliding Mode Control approach based on a doubly fed Induction Generator power (DFIG-Generator) in order to reduce the response time of the wind system and extract the maximum power from wind energy [23].

In this paper, three types of the control systems are designed to construct the pitch variable-speed control: conventional PI controller, Neurofuzzy controller and modified PI-Neurofuzzy controller. The performance of each controller is designed and studied by utilizing the MATLAB Simulink toolbox. The results show that the proposed controller (the modified PI-Neurofuzzy controller) succeeds to keep the speed of the rotor around the rated value $(1.86 \mathrm{rad} / \mathrm{s})$ even the wind speed change suddenly from $13 \mathrm{~m} / \mathrm{s}$ to $18 \mathrm{~m} / \mathrm{s}$. It is mean that the generated power from the wind turbine is kept constant even the speed of the wind rises up the rated value.

The paper is organized as follows. The wind turbine model is derived in Section 2. In Section 3, the model of hydraulic pitch actuator is presented. The design of pitch angle control systems are discussed in Section 4. The simulation results are discussed in Section 5. Finally, the conclusion is given in Section 6.

\section{WIND TURBINE MODEL}

The wind turbine performs three main tasks: the first task is extracting the electrical power from the wind energy. The parts responsible for achieving this task are rotor hub and blades. The rotational movement of the rotor is transmitted to the generator via the gear box to increase its revolutions per minute. The second task is converting the extracted mechanical power to electrical power by using electrical generator. Finally, the generated electrical power is sent to a power grid. The power generated from the generator is a function of input wind speed.

The angle of the blades is adjusted by a pitch angle control system to optimize the generated power from the turbine when the wind speed is less than the rated wind speed. While, when the wind speed is higher than the rated wind speed, the pitch angle control system adjusts the blade angle to keep the generated power at rated turbine power. The desired position of the blades is adjusted by employing an electric or hydraulic pitch servo motors.

In this paper, it is assumed that the input wind speed is higher than the rated wind speed of the turbine. The relationship between the mechanical power and input wind speed is shown as below:

$$
P_{m}(u)=\frac{1}{2} C_{p o}(\gamma, \beta) \rho \pi R^{2} u^{3}
$$

where: $C_{p o}(\gamma, \beta)=$ the power coefficient of the turbine

$\gamma=$ the tip-speed ratio

$\beta=$ the pitch angle

$\rho=$ the air density

$R=$ the radius of the rotor

$u=$ the wind speed. 
There are different equation forms to compute the value of power coefficient of the wind turbine. In this paper, the following equation is used to calculate the value of $C_{p o}(\gamma, \beta)[24]$ :

$$
C_{p o}(\gamma, \beta)=0.5176\left(\frac{116}{\vartheta}-0.4 \beta-5\right) e^{\frac{-21}{\vartheta}}+0.0068 \gamma
$$

where $\vartheta$ is tip ration it can be calculated from the following equation:

$$
\frac{1}{\vartheta}=\frac{1}{\gamma+0.08 \beta}-\frac{0.035}{\beta^{3}+1}
$$

As shown from the (2), the power coefficient is nonlinear equation and it depends on the tip-speed ratio $(\gamma)$ and the pitch angle $(\beta)$. The tip-speed ratio $(\gamma)$ is the ratio between the blade tip speed and the wind speed as shown in the following equation [24]:

$$
\gamma=\frac{\omega_{r} L}{u}
$$

where: $\omega_{r}=$ the turbine rotor speed.

$L=$ the turbine blade length.

From (4), the rotation of the rotor is proportional to the wind speed. So that the power extracted by the wind turbine is increased when the wind speed increase. When the wind speed reaches to rated wind speed, the mechanical power extracted by the wind turbine reaches to the rated power of the turbine. If the wind speed rises up the rated value, the mechanical power should be kept constant to avoid crashing of the wind turbine. The pitch angle control system is adjusted the blades angle $\beta$ to avoid crashing.

The relationship between the aerodynamic torque coefficient $T_{c}$ and the mechanical power is given by the following equation:

$$
T_{c}=\frac{P_{m}}{\omega_{r}}
$$

Substituting (1) in (2), we yield that:

$$
T_{c}=0.5 \frac{C_{p o}(\gamma, \beta)}{\omega_{r}} \rho \pi R^{2} u^{3}
$$

\section{HYDRAULIC PITCH ACTUATOR MODEL}

The pitch actuators are used to turn the blades of the wind turbine around their longitudinal axis to keep the extracted mechanical power within the rated value. The hydraulic pitch actuator model describes the relationship between the pitch demand $\beta_{d}$ from the pitch controller and the actual value of the pitch angle $\beta$. In this paper, the actuator model is assumed as a first order system as shown in below:

$$
\frac{\beta(s)}{\beta_{d}(s)}=\frac{1}{\tau_{b^{s+1}}}
$$

where: $\tau_{b}=$ time constant of pitch actuator.

\section{PITCH ANGLE CONTROL SYSTEM DESIGN}

In this work, three controller systems are designed to generate the control signals as input to the hydraulic pitch actuators to adjust the position of the blades. Then, the comparisons of the responses of the wind turbine with each controller are made.

Fist controller is selected as classical PI controller. Figure 1 shows the connection of the PI controller with wind turbine.

The input of PI controller is the error between the actual value of the turbine rotor speed and the reference rotor speed. The PI controller generates the controller signal (the pitch demand $\beta_{d}$ ) which is used as input to the actuator. The pitch demand $\beta_{d}$ is computed from the following equation:

$$
\beta_{d}=K_{p} E(t)+K_{i} \int \quad E(t) d t
$$


where: $K_{p}=$ the proportional gain of controller

$K_{i}=$ the integral gain of controller.

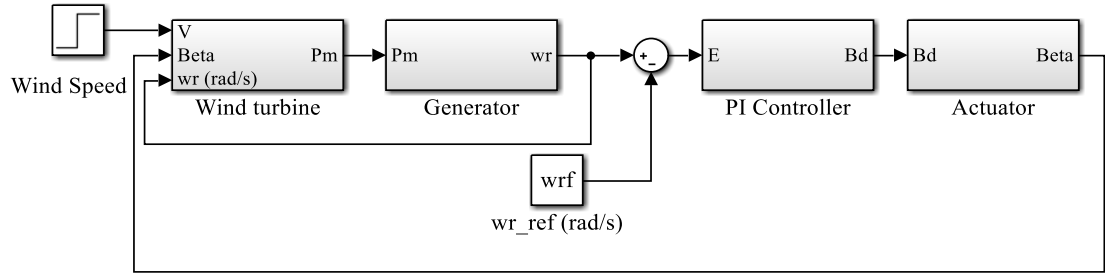

Figure 1. The connection of PI controller with wind turbine

According to (7), the actuator generates the pitch angle $\beta$ to adjust the blades of the wind turbine. The second designed controller is Neurofuzzy controller. The neurofuzzy controller is selected in this work instead of the fuzzy controller because the neurofuzzy controller combines the attributes of both fuzzy system and neural network. The neurofuzzy controller uses the features of optimization technique of neural network to train the parameters of fuzzy system [25]. Figure 2 shows the connection of Neurofuzzy controller with the wind turbine system. As demonstrated from Figure 2, the Neurofuzzy controller is used as an inverse model to generate the pitch demand signal $\beta_{d}$.

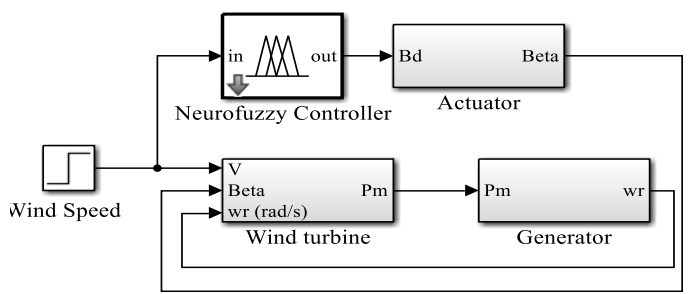

Figure 2. The connection of Neurofuzzy controller with wind turbine

For the Neurofuzzy controller designing, the selection of the fuzzy system completely depends on the data training method to compute the pitch demand. The collected data from the PI controller are used for training the Neurofuzzy controller by using the hybrid optimization method which is the combination of gradient and least square estimate method.

The third controller that is designed in this work is modified PI-Neurofuzzy controller. Figure 3 shows the connection of modified PI-Neurofuzzy controller with a wind turbine.

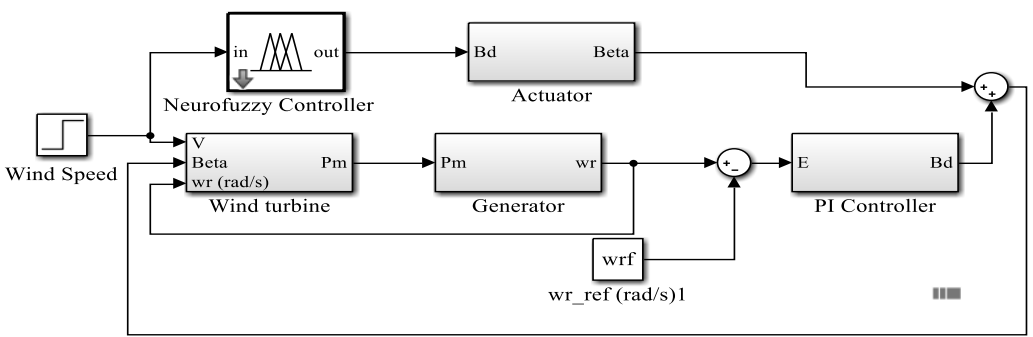

Figure 3. The connection of modified PI-Neurofuzzy controller with wind turbine

The designed Neurofuzzy controller in the second controller is used to generate pitch demand $\beta_{d}$. Then the pitch actuator uses the output of the Neurofuzzy controller to calculate the pitch angle $\beta$. Finally, the output of the PI controller is added to the output of the pitch actuator to generate the adjusted signal for the blades of wind turbine. 


\section{RESULTS AND ANALYSIS}

In this work, the speed controller of the wind turbine is discussed. The wind speed is assumed higher than the rated speed of the wind turbine. So that, the pitch angle of the blades should be adjusted to avoid the crashing of wind turbine. For comparison purposes, three pitch angle control systems are designed in this work. The pitch angle control systems of the wind turbine are simulated by employing a MATLAB program to test the performance of the designed controllers and evaluated the efficiency of the wind turbine.

The nominal physical parameters of $5 \mathrm{MW}$ wind turbine, which are used in the simulation work, are shown in Table 1 [26]. The wind speed which is used in this work is equal to $18 \mathrm{~m} / \mathrm{s}$, while the rated wind speed of the turbine under studied is $12 \mathrm{~m} / \mathrm{s}$. Therefore, the rotational speed should be kept almost constant around the rated rotor speed $\left(\omega_{\text {r-ref }}=1.86 \mathrm{rad} / \mathrm{s}\right)$.

Table 1. The Nominal Physical Parameters

\begin{tabular}{ll}
\hline Description of the parameter & \multicolumn{1}{c}{ Value } \\
\hline Rated turbine power & $5 \mathrm{MW}$ \\
Rated wind speed & $12 \mathrm{~m} / \mathrm{s}$ \\
Rated rotor speed & $1.86 \mathrm{rad} / \mathrm{s}$ \\
Number of blades & 3 \\
Gear box ratio & 60.88 \\
Turbine blade length & $55 \mathrm{~m}$ \\
Radius of rotor & $30 \mathrm{~cm}$ \\
Air density & $1.225 \mathrm{~kg} / \mathrm{m}^{3}$ \\
\hline
\end{tabular}

For designing of PI controller, the value of $K_{p}$ and $K_{i}$ are selected equal to 1000 . The wind turbine with PI controller is simulated by using Matlab simulink toolbox at rated turbine power and rated rotor rotation speed to collect the data for training the Neurofuzzy controller. The number of membership functions for Neurofuzzy system is equal to five which have triangle shape. The hybrid optimization method is used to train the parameters of Neurofuzzy system. Figure 4 shows the training phase of Neurofuzzy system.

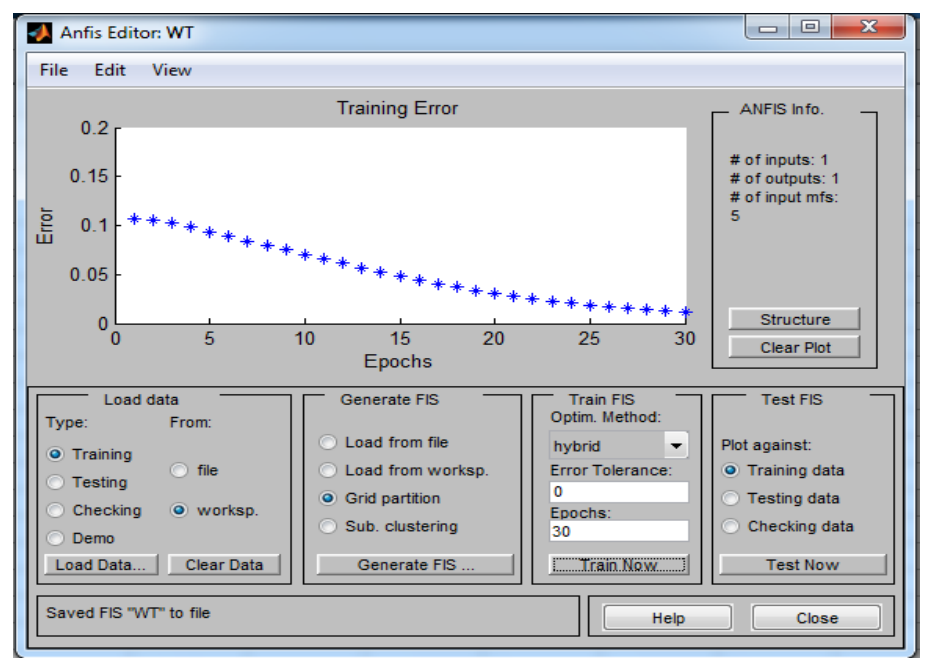

Figure 4. The training phase of Neurofuzzy system

In this simulation, it is assumed that, the wind speed is varied from $13 \mathrm{~m} / \mathrm{s}$ to $18 \mathrm{~m} / \mathrm{s}$. The step function is used to simulate the changing of the wind speed as shown in Figure 5. The pitch angles of the blades are adjusted using the designed control systems to avoid crashing of the wind turbine. Figure 6 shows the comparison between the time response of the pitch angle $\beta$ when the three designed controllers (PI controller, Neurofuzzy controller and PI-Neurofuzzy controller) are used.

Figure 6 illustrates the rotation speed change of the rotor when the three designed controllers are used. The robust controller should keep the rotation speed of the rotor constant even the wind speed changed. Figure 7 shows that, when the PI-Neurofuzzy system is used the rotational speed of the rotor is almost kept constant. It is mean that the new proposed controller is more efficient than the other controllers. 


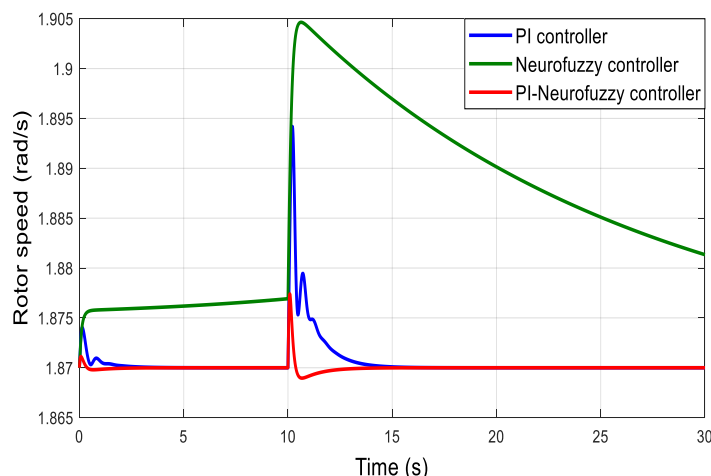

Figure 5. Comparison of pitch angle change when the three different controllers are used

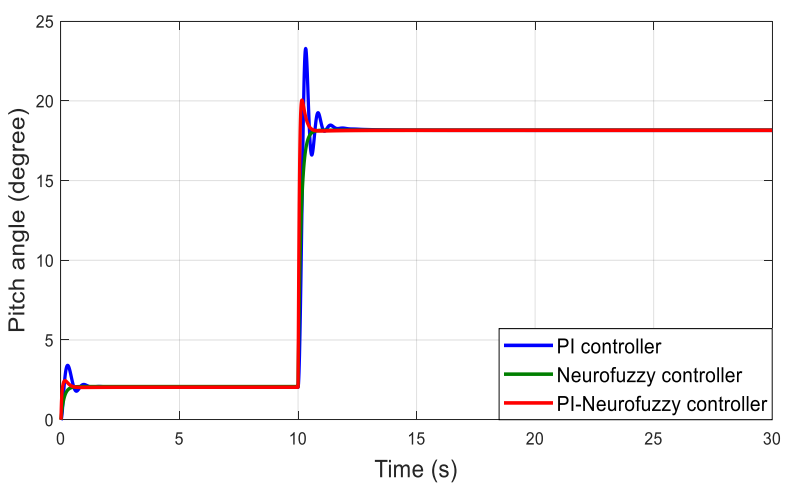

Figure 6. Comparison of rotation speed change of the rotor when the three different controllers are used

Figure 7 shows the comparison of mechanical power change when the three different controllers are used. As it is mentioned above, the mechanical power should be kept constant to avoid crashing of the wind turbine. When the PI-Neurofuzzy system is used, the mechanical power is almost kept contasnt around the rated turbine mechanical power $(5 \mathrm{MW})$ even the wind speed is varied from $13 \mathrm{~m} / \mathrm{s}$ to $18 \mathrm{~m} / \mathrm{s}$. The result illistrates that, the response of new proposed controller is better than the responses of the other two controller.

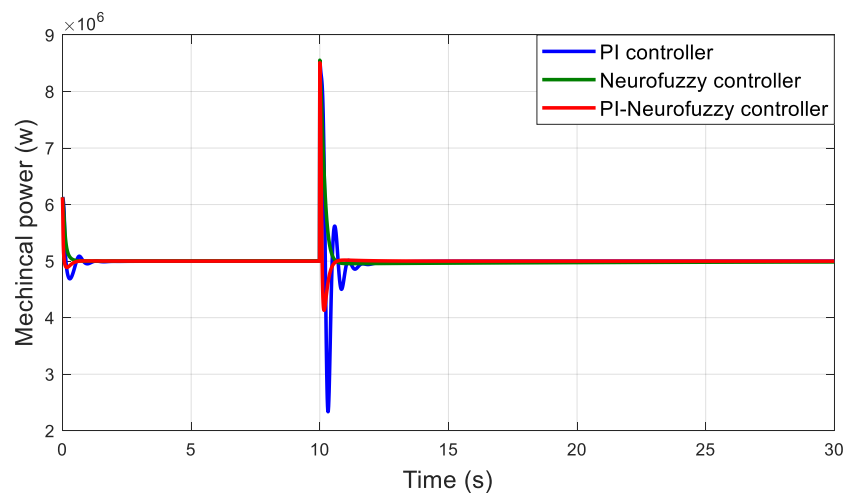

Figure 7. Comparison of mechanical power change when the three different controllers are used

\section{CONCLUSION}

The wind turbines are one of the renewable systems that are used to generate the electricity from wind energy. When the wind speed is higher than the rated speed of the turbine, pitch angle of the blades should be adjusted to maintain the rotation speed of the generator almost constant even the wind speed is higher than the rated wind speed. In this paper, three different controllers are designed to achieve this task. The results show that, the modified PI-Neurofuzzy controller is more robust than the other designed controller because when this controller is used as a pitch angle control system, the rotational speed is almost maintained constant even the wind speed rises up the rated wind speed.

\section{REFERENCES}

[1] "Energy Harvesting Solar, Wind, and Ocean Energy Conversion Systems", Taylor and Francis Group, ISBN 978-14398-1508-3, USA, 2010.

[2] C. Wook Lim, "Design and Manufacture of Small-Scale Wind Turbine Simulator to Emulate Torque Response of MW Wind Turbine", International Journal of Precision Engineering And Manufacturing-Green Technology, Vol. 4, No. 4, Pp. 409-418, 2017.

[3] N. Bouchiba, A. Barkia, S. Sallem, L. Chrifi-Alaoui, S. Drid, and M.B.A. Kammoun, "Implementation and comparative study of control strategies for an isolated DFIG based WECS" The European Physical Journal Plus, Vol. 132, No. 415, pp. 1-13, 2017. 
[4] M. A. Soliman, H M. Hasanien, H. Z. Azazi1, E. E. El-Kholy, and S. A. Mahmoud, "Linear-Quadratic Regulator Algorithm-Based Cascaded control Scheme for Performance Enhancement of a Variable-Speed Wind Energy Conversion System" Arabian Journal for Science and Engineering, 2018.

[5] D. Ounnas, M. Ramdani, S. Chenikher, and T. Bouktir, "An Efficient Maximum Power Point Tracking Controller for Photovoltaic Systems Using Takagi-Sugeno Fuzzy Models” Arab J Sci Eng, Vol. 42, pp. 4971-4982, 2017.

[6] A. Joudaa,F. Elyesb, A. Rabhic, and M. Abdelkaderb, "Optimization of Scaling Factors of Fuzzy-MPPT Controller for Stand-alone Photovoltaic System by Particle Swarm Optimization," Energy Procedia, Vol. 111, pp. 954-963, 2017.

[7] Ammar A. Aldair, A. A. Obedb, A. F. Halihala, "Design and implementation of ANFIS-reference model controller based MPPT using FPGA for photovoltaic system", Renewable and Sustainable Energy Reviews, Vol. 82, pp. 2202-2217, 2018.

[8] Ruchira, Patel R.N., Sinha S.K. (2019) "Comparison of ANN-Based MPPT Controller and Incremental Conductance for Photovoltaic System". In: Nath V., Mandal J. (eds) Proceeding of the Second International Conference on Microelectronics, Computing \& Communication Systems (MCCS 2017). Lecture Notes in Electrical Engineering, vol 476. Springer, Singapore.

[9] F. Chekireda, C. Larbes, D. Rekioua, F. Haddad, "Implementation of a MPPT fuzzy controller for photovoltaic systems on FPGA circuit", Energy Procedia, Vol. 6,pp. 541-549, 2011.

[10] G. Giorgi, John V. Ringwood, "Implementation of latching control in a numerical wave tank with regular waves", J. Ocean Eng. Mar. Energy, Vol. 2, pp. 211-226, 2016.

[11] Y. Vidal, L. Acho, N. Luo, M. Zapateiro and F. Pozo, "Power Control Design for Variable-Speed Wind Turbines," Energies, vol. 5, pp. 3033-3050, 2012.

[12] C. Jauch, S. Islam, P. Sorensen and B. Jensen, "Design of a wind turbine pitch angle controller for power system stabilization," Elsevier Trans. Renewable Energy, vol. 32, pp. 2334-2349, 2007.

[13] D. Petkovic, Z. Cojbasic and V. Niklic, "Adaptive neuro-fuzzy approach for wind turbine power coefficient estimation,” Elsevier Trans. Renewable and Sustainable Energy Reviews, vol. 28, pp. 191-195, 2013.

[14] K. Angeline, T. Pidikiti,and S. Yadlapati," Modelling and Simulation of ANFIS Controlled Doubly FED Induction Generator Based Wind Energy System for Performance Enhancement," IJCTA, vol. 10, No. 5, pp. 61-73, 2017.

[15] Z. Chen, S. A. Gomez, M. McCormick, "A fuzzy logic controlled power electronic system for variable speed wind energy conversion systems", Eighth International Conference on Power Electronics and Variable Speed Drives, Publication No. 475, 2000.

[16] A. G. Abo-Khalil, D. Lee, J. Seok, "Variable speed wind power generation system based on fuzzy logia control for maximum output power tracking”, 35th Annual IEEE Power Electronics Specialists Conference, Achen, Germany, 2004.

[17] C. Jauch, T. Cronin, P. Sørensen, B. B. Jensen, "A fuzzy logic pitch angle controller for power system stabilization", Wind Energy, 2007, pp. 19-30.

[18] J. Zhang, M. Cheng, Z. Chen and X. Fu, "Pitch Angle Control for Variable Speed Wind Turbines," DRPT2008 Third International Conference on Electric Utility Deregulation and Restructuring and Power Technologies, 6-9 April 2008, Nanjing China.

[19] D. Chung phan and T. Hieu Trinh, “ Maximum power Extraction mwthod for Doubly-fed Induction Genrerator Wind Turbine" International Journal of Electrical and Computer Engineering (IJECE), vol.8,No. 2, pp. 711-722, 2018.

[20] K. Rabyi, and H. Mahmoudi, "Energy storage of DFIG based wind farm using D-STATCOM" International Journal of Electrical and Computer Engineering (IJECE), vol. 9, No. 2, pp. 761-770,2019.

[21] S. Ruiz, J. Patino and J. Espinosa, "PI and LQR controllers for Frequency Regulation including Wind Generation" International Journal of Electrical and Computer Engineering (IJECE), Vol. 8, No. 5, pp. 3711-3721, 2018.

[22] K. Belgacem, A. Mezouar and N. Essounbuli, "Design and Analysis of Adaptive Sliding Mode with Exponential Reaching Law Control for Double-Fed Induction Generator Based Wind Turbine" International Journal of Power Electronics and Drive System (IJPEDS), vol. 9, No. 4, pp. 1534-1544, 2018.

[23] Y. Ihedrane, C. El Bekkali, B. Bossoufi and M. El Ghamrasni, 'Improved Wind System using Nonlinear Power Control" Indonesian Journal of Electrical Engineering and Computer Science (IJEECS), vol. 14, No. 3, 2019.

[24] A. Hwas and R. Katebi, "Wind Turbine Control Using PI Pitch Angle Controller," 2nd IFAC Conference on Advances in PID Control, vol. 45, No. 3, pp. 241-246, 2012.

[25] Ammar A. Aldair and W.J. Wang "Adaptive neuro fuzzy inference controller for full vehicle nonlinear active suspension systems" $20101^{\text {st }}$ International Conference on Energy, Power and Control (EPC-IQ), pp. 97-106, 2010.

[26] Wang C. "Control, stability analysis and grid integration of wind turbines". PhD Thesis, Imperial College London, 2008. 